\title{
NARRAÇÃO E SUBJETIVIDADE EM WALTER BENJAMIN
}

\author{
Mariana Caldas Pinto Ferreira
}

\begin{abstract}
RESUMO
Este artigo pretende desenvolver como o conceito de narrar histórico não apenas propõe uma alternativa à filosofia da história como também potencializa uma concepção de ontologia da ação a qual considera a ruptura da linearidade histórica e a construção de um mundo comum.
\end{abstract}

Palavras-chave: Narrativa - Ação Política - Subjetividade - História

\section{NARRATIVE AND SUBJECTIVITY IN WALTER BENJAMIN}

\begin{abstract}
This article will develop on the manner though which storytelling concept not only proposes an alternative historiography but also enhances an action ontology, which considers both the historical linearity rupture and a construction of a word in common among subjectivities
\end{abstract}

Key-words: Narrative, Political action, Subjectivity, History

\section{Narração e Subjetividade em Walter Benjamin}

Este trabalho se detém na concepção de narração em Walter Benjamin, com o objetivo de compreender uma ontologia de ação política baseada nas narrativas individuais. Para tanto, este trabalho parte do pressuposto de uma crise de referenciais do século XX como fundamento para Benjamin repensar outras formas de narrativa diante da emergência da mídia, propaganda e jornais. Além disso, narrar é uma prerrogativa de um sujeito situado historicamente, não como resultado de fenômenos históricos autossuficientes ou até mesmo de Sittlichkeit hegeliana, mas sim como aquele que inicia processos e rupturas em comunidades políticas. O anseio norteador será de, portanto, compreender como 
a capacidade de narrar, em Benjamin, pode fundamentar uma ética de ação política.

\section{Crise política e história}

A crise da tradição - resultante da quebra da promessa da modernidade - foi o diagnóstico a qual muitos autores chegaram ao pensar os fenômenos do século $X X$ e sua condição nela enquanto intelectuais e políticos. Tal qual o "O Ovo da Serpente" no qual Bergman realiza uma paródia de que o ovo da serpente revela uma criatura horripilante na membrana que a protege, os tempos que se apresentam no século XX parece prometer um monstro até então não revelado na história ocidental. Nesse momento, Walter Benjamin, um curioso colecionador de objetos e coisas incomuns, estava entre um desses intelectuais (SONNTAG, 1986, 93). Na verdade, o interesse pelas coisas onde ninguém procurava nos revela uma característica peculiar no estilo do pensamento benjaminiano: o interesse pelas pequenas narrativas, pelos terrenos baldios, pela infância - isto é, tudo aquilo que não remonta à consciência moral e autoafirmativa tanto kantiana quanto hegeliana.

Em "Alarme de Incêndio", Benjamin já parece anunciar aquilo que seria a temática onipresente em "Teses sobre a História", escrito nas vésperas do seu suicídio. O pequeno fragmento de "Rua de Mão Única" revela uma preocupação com o autor com a promessa da luta de classes, no qual a vitória dos vencidos seria eminente e resolveria os rumos da história ocidental. O que aparece antes como preocupação interna sobre o marxismo, se torna um prognóstico sombrio em "Teses sobre a História", especialmente no que tange a condição humana na modernidade. "Era meia noite no século" e não havia nenhuma luz a que pudesse recorrer. Esse quadro aterrador instiga à Benjamin a refletir sobre a concepção de tempo, espaço e memória que estruturava o imaginário político da Europa, propondo uma cisão à essa leitura histórica da humanidade (LÖWY, 2005, 33-35). Portanto, Benjamin expressa um pensamento que rompe com os referenciais teóricos vigentes ao constatar que a tradição não parecia oferecer fundamentos para compreender a profunda crise do século. Ou que, ao menos, pudesse dar algum sentido nessa perda de referenciais.

Doutoranda em Relações Internacionais no Instituto de Relações Internacionais da PUC-Rio e mestre em Direito Constitucional e Teoria do Estado pela mesma instituição. Brasileira, residente no Rio de Janeiro, 
Ao propor uma relação diferenciada do passado, contrária a uma filosofia da história, Benjamin avança na concepção de rememoração, no qual não significa simplesmente a capacidade de lembrar o sofrimento daqueles que já se foram e que temos o dever de lembrar; mas sim a emancipação desses oprimidos que só se alcança quando a redenção atua em conjunto com a reparação da dor - tikun" (LÖWY, 2005, 51). "A redenção messiânica/revolucionária é uma tarefa que nos foi atribuída pelas gerações passadas. Não há um Messias enviado do céu: somos nós o messias" (LÖWY, 2005, 51). Isso significa dizer, então, que o messianismo na leitura de Löwy se encarna de forma coletiva e na humanidade oprimida. Por isso que tanto rememoração quanto a redenção não são atitudes de voltar-se para o passado para lamentar o que aconteceu, mas, sobretudo, para encontrar as forças nele que o tragam para o presente. Isto é, o passado como elemento transformador do presente (LÖWY, 2005, 51-52).

Logo, o messianismo em Benjamin significa um acontecimento único e veloz que rompe drasticamente com o desenrolar das coisas, mas que carrega em si uma história ainda maior e mais complexa: cada estória contada por cada oprimido. Mas ele só se torna messiânico quando imputa no presente o momento de realizar a revolução (MATE, 1991, 185). Esse mecanismo de interrupção da história é, para Benjamin, o legado mais precioso que a modernidade deixou. $A$ questão não é destruir por destruir, mas destruir para permitir o novo (MATE, 1991, 185): "O passado espera de nós sua redenção" (LÖWY, 2005, 54) permitindo que cada vítima não seja mais esquecida e consiga se emancipar.

O passado não pode ser um conhecimento privilegiado da historiografia porque ele precisa ser um espaço de intervenção política do presente (LÖWY, 2005, 63-64). Além disso, recuperar o passado é o espaço onde se decide o futuro, para Mate (MATE, 1991, 209). Trazer o passado no presente transforma a forma até então assumida pelo passado e transforma o presente ao oferecer esperança de comprimir promessas anteriores e esquecidas (LÖWY 2005, 6364). O historiador é qualquer um, voltado para as pequenas narrativas

\footnotetext{
1 Tikun significa, no hebraico, o retorno de todas as coisas no seu estado inicial - uma restitutio ad integrum (Löwy, 2005, 55-56).

Doutoranda em Relações Internacionais no Instituto de Relações Internacionais da PUC-Rio e mestre em Direito Constitucional e Teoria do Estado pela mesma instituição. Brasileira, residente no Rio de Janeiro, Brasil. E-mail: mferreira2812@gmail.com
} 
esquecidas dos oprimidos, que não possui monopólio da verdade histórica e que é interpelado pela visão furtiva (como um relâmpago) do passado que precisa ser rememorado (LÖWY, 2005, 64). ${ }^{2}$

É justamente essa imagem fugaz, esse relâmpago, essa lembrança que salva e sensibiliza o olhar reflexivo à história que é contada (LÖWY, 2005, 6566). A história pode ser uma lista de derrotas imensas, mas existe sempre pequenos núcleos de resistência que impossibilitam uma concepção de verdade única na história. O momento de perigo maior, é o momento onde o passado se liga ao presente e cria as condições de possibilidade para a redenção e a revolução (LÖWY, 2005, 68-69).

Por isso, Benjamin se interessa pela potência das pequenas histórias e narrativas pessoais - com um certo lamento, especialmente, por constatar que é uma tradição que se perde ${ }^{3}$. Por exemplo, a parábola do pai sobre uma riqueza oculta no seu vinhedo, contada aos filhos no seu leito de morte, nos remete à uma experiência sobre as coisas mundanas que se perdeu: "Quem encontra ainda pessoas que saibam contar histórias como elas devem ser contadas?" pergunta Benjamin em "Experiência e Pobreza". Certamente, não se trata de uma nostalgia ao passado e à tradição oral - mas sim uma proposta de concepção de subjetividade e ser-no-mundo em um tempo fraturado, no qual a capacidade de narrar pode assumir uma potência de realização e reconciliação com o mundo compartilhado com outros indivíduos. Afinal, os indivíduos não estão isolados entre si. A narrativa só existe quando há um ouvinte e é dessa forma que o vínculo comunitário e sua história se desenrolam (GAGNEBIN, 2010, 11).

\footnotetext{
2 "Articular historicamente o passado não significa reconhece-lo 'tal como ele foi'. Significa apoderarmo-nos de uma recordação (Erinnerung) quando ela surge como um clarão num momento de perigo. Ao materialismo histórico interessa-Ihe fixar uma imagem do passado tal como ela surge, inesperadamente, ao sujeito histórico no momento do perigo. O perigo ameaça tanto o corpo da tradição como aqueles que a recebem. Para ambos, esse perigo é um: o de nos transformarmos em instrumentos das classes dominantes" (Benjamin, tese VI, 2010a, 11).

${ }^{3} \mathrm{Em}$ defesa do cronista contra a figura do historiador, Benjamin anuncia "o cronista que narra os acontecimentos, sem distinguir entre os grandes e os pequenos, leva em conta a verdade de que nada do que um dia aconteceu pode ser considerado perdido para a história" (Benjamin, tese III, 2010a, 7).
}

Doutoranda em Relações Internacionais no Instituto de Relações Internacionais da PUC-Rio e mestre em Direito Constitucional e Teoria do Estado pela mesma instituição. Brasileira, residente no Rio de Janeiro, 


\section{Experiência fragmentada}

A narrativa, em Benjamin, não é um simples contar de estórias - pois, contar algo implica um caminho sem destino. Em "Experiência e Pobreza", se lê uma constatação sombria do fracasso da experiência que é necessariamente atrelado ao fracasso da narrativa moderna. Não à toa, o início do fragmento começa com a experiência da narração do pai em seu leito de morte aos seus filhos.

Contudo, a linguagem em Benjamin não abarca em si um sentido a priori - ela é o vínculo mais profundo da construção do mundo em comum, especialmente porque ela não detém um sentido em si própria. Ao contrário da linguística tradicional platônica, a construção do sentido da linguagem é aberta. O indivíduo não adestra a linguagem. Em diálogo com os românticos de lena, Benjamin não lê a linguagem como um dispositivo de comunicação, mas "como ferramenta a serviço de causas exteriores a ela" (DUARTEe, 2011, 146). Ainda que ao se referir ao movimento Sturm und Drang Benjamin esteja pensando sobre a condição de escrita - e daí a preocupação com a tradução e leitura do autor, pode-se inferir que a transmissão oral contenha essa mesma característica de sentido aberto, visto que a "linguagem [...] deixa de ser representação do pensamento e de experiências, para ser, ela mesma, pensamento e experiência" (DUARTE, 2011, 146). Nesse sentido, ao retirar um propósito a priori da linguagem, e, portanto, retirando qualquer tentativa de representatividade, abre-se sua potência para múltiplos significados e construção de sentido. Isso não implica dizer que tudo se resuma à discurso e relatividade, mas sim que a experiência do mundo ocorre dentro da linguagem, e não por meio da mesma.

Ora, mas a concepção de uma linguagem aberta e com um sentido a ser definido pelos sujeitos implica uma concepção de política própria, no qual o indivíduo forma sua subjetividade constantemente pelo processo de construção de um mundo comum com outros indivíduos. A subjetivação ocorre na narrativa, na construção de vínculos, no processo de esquecimento e rememoramento uma outra concepção da história humana que não cai nas armadilhas do progresso da filosofia da história. Esse ponto será recuperado posteriormente 
neste artigo ao associar a capacidade de narrar eventos e a própria história de vida enquanto uma ontologia de ação política no mundo.

Por ora, cabe ressaltar que no fragmento "Experiência e Pobreza", Benjamin alerta sobre o fim da narração tradicional: "Ficamos pobres". Pobres devido ao avanço da técnica, de uma nova estrutura midiática de contar histórias e a "aspiração dos homens em libertam-se de toda experiência". Experiência, em Benjamin, deve ser compreendida como a nossa sensibilidade de apreender o mundo - as coisas e a natureza - de forma a compreender que, ao contrário do adestramento da natureza pelo homem proferido pela filosofia ocidental, os indivíduos não adestram a paisagem à sua volta. Os objetos diminuem nossa potência subjetivante.

O fim da experiência (Verfall der Erfahung) implica na perda da tradição ressignificada a cada geração de filhos, transmitida pelos pais, isto é, uma "tradição compartilhada por uma comunidade humana" (GAGNEBIN, 2009, 50). Como Gagnebin argumenta, não se trata de uma lição moral sobre a mensagem paterna aos filhos em relação à sua herança no vinhedo. Se trata, sim, da transmissão de uma experiência, de um tesouro escondido - aquilo que transcende as experiências individuais particulares e que transcende a vida e a morte, consequentemente (Idem, 2009, 50). É o desaparecimento, então, das narrativas que constroem o fluxo de continuidade de comunidades políticas.

Contudo, enquanto, por um lado, "Experiência e Pobreza" apresenta uma observação pessimista em relação às formas de narrar a experiência histórica, especialmente quando Benjamin considera a incapacidade de fala dos sobreviventes da $1^{\text {a }}$ Grande Guerra, o fragmento "O Narrador" se detém em uma proposta de uma outra narrativa - "uma narração nas ruínas da narração" (Idem, 2009, 53). Assim como em "Experiência e Pobreza", no fragmento sobre o narrador, Benjamin argumenta que "[...] a experiência da arte de narrar está em vias de extinção. São cada vez mais raras as pessoas que sabem narrar devidamente". 4

\footnotetext{
${ }^{4}$ Aqui uma ressalva: as obras escolhidas - "Experiência e Pobreza" e "O Narrador" - que parte da mesma percepção de extinção da experiência, são obras que realizam uma crítica à gêneros literários e, portanto, a escrita. Mas, como a palavra narrar vem do alemão Erzählen que significa narrar e contar em geral não está presa na voz narrativa do texto (Gagnebin, 2014, 220). Por Doutoranda em Relações Internacionais no Instituto de Relações Internacionais da PUC-Rio e mestre em Direito Constitucional e Teoria do Estado pela mesma instituição. Brasileira, residente no Rio de Janeiro, Brasil. E-mail: mferreira2812@gmail.com
} 
Nesse ensaio, Benjamin, novamente, argumenta que os narradores recorrem à experiência da transmissão. O sintoma da decadência é o desuso dos conselhos como fonte da sabedoria, que guarda em si a "esfera do discurso vivo e ao mesmo [...] uma nova beleza ao que está desaparecendo". Nessa linha, Arendt lembra que a sabedoria é uma virtude da velhice - por aqueles que já viveram e viram histórias e contam suas experiências (Arendt, 2008, 120). É importante destacar que o narrador aparece associado à figura do Justo, tal que em "Teses sobre a História". Isso se justifica porque, como já explicitado, o narrador em Benjamin não é o sujeito detentor da verdade totalitária do passado; ao contrário, há uma pretensão mais humilde do narrador - nos termos da Gagnebin -, pois o narrador não possui autoridade absoluta em relação à história que é contada. O narrador é impreciso, fugaz, sem sintaxe. Justamente porque o que ele revela é muito frágil - e, por isso, o ouvinte também possui um papel relevante ao ouvir histórias. A autoridade do narrador advém da morte - contar sobre aqueles que viveram, ou, em outras palavras, iluminar aqueles invisíveis das grandes narrativas historiográficas. Por isso, a figura do cronista como narrador da história.

Interessante ressaltar que o contar histórias está intimamente ligado à memória:

Não se percebeu devidamente até agora que a relação ingênua entre o ouvinte e o narrador é dominada pelo interesse em conservar o que foi narrado. [...] A memória é a mais épica de todas as faculdades. Somente uma memória abrangente permite à poesia épica apropriarse do curso das coisas, por um lado, e resignar-se, por outro lado, com o desaparecimento dessas coisas, com o poder da morte (O Narrador, Benjamin, 2010, 210).

Portanto, rememorar e esquecer são duas faces de um mesmo processo na narração. O dom de narrar "é o poder contar sua vida; sua dignidade é contála inteira”. Mas, para além disso, o processo de narrar algo implica na formação do sujeito na sua ligação com os outros, na construção de um sentido de mundo.

Por isso, contar sobre si é uma defesa da rememoração, não enquanto fidelidade ao passado, mas, sobretudo, à transformação do presente. No tempo

isso, a justificativa das obras escolhidas, pois todas se preocupam com a capacidade de contar histórias - objeto deste trabalho, ainda que mais voltado a capacidade de falar.

Doutoranda em Relações Internacionais no Instituto de Relações Internacionais da PUC-Rio e mestre em Direito Constitucional e Teoria do Estado pela mesma instituição. Brasileira, residente no Rio de Janeiro, 
messiânico benjaminiano, não se trata fazer sentido as distinções espaciais do tempo enquanto passado, presente e futuro. Ao contrário, não há distinção evidente, pois os elementos temporais se mesclam em um tempo presente (ASSY, 2013). Como Sontag afirma ao descrever o comportamento saturnino de Benjamin, a experiência para o autor deve ser vista enquanto uma ruína. Logo, compreender algo é compreender sua topografia e saber como mapeá-la (SONNTAG, 1986, p. 90). Em outras palavras, compreender o sujeito histórico é compreender sua ruína - a desorientação em relação aos tempos passado, presente e futuro. O narrador se encarna na figura do justo justamente porque resgata as narrativas invisíveis e esquecidas, passíveis, novamente, de esquecimento. Em llíada, o momento de interrupção narrativa ocorre no momento de afirmação de Ulisses enquanto herói - quando é instaurado o "catálogo das damas" (isto é, a citação da longa lista de heroínas mortas) e quando Ulisses narra a história de Agamémnon, uma história que não foi contada pela llíada (GAGNEBIN, 2014, 25). Quanto mais se narra, mais tornam-se presentes aqueles que não estão. Como afirma Gagnebin sobre a passagem acima: "Essa é a função secreta, mas central, de Ulisses, figura, no própria poema, do poeta, daquele que sabe lembrar, para os vivos, os mortos" (Idem, 2009, 27). Narrar é a possibilidade de oferecer redenção aos mortos, portanto.

A narrativa é aspecto fundamental na obra benjaminiana porque a transmissão guarda um tesouro a ser descoberto: a sensibilização à experiência que está em vias de extinção com os romances e jornais modernos. É por meio dela que nos reconciliamos com o mundo em comum - com os objetos à nossa volta, à nossa condição histórica e aos nossos laços de pertencimento - e é por meio dela que nos constituímos enquanto sujeitos políticos. É por meio da narrativa, enfim, que honramos e damos sentido à nossa existência vinculada a uns outros, mortos e vivos. A perda da experiência não é um diagnóstico nem fatalista nem nostálgico, acredito, mas sim uma condição contemporânea que nos faz viver a narrativa enquanto ruína e potência transformadora.

\section{Narrar e contar histórias}

Até então, meu esforço foi o de contextualizar a obra do Benjamin no seu tempo que, porém, assim como Arendt ao contar as histórias de alguns dos Doutoranda em Relações Internacionais no Instituto de Relações Internacionais da PUC-Rio e mestre em Direito Constitucional e Teoria do Estado pela mesma instituição. Brasileira, residente no Rio de Janeiro, 
indivíduos que lançaram uma luz em tempos abandonados pela tradição, a obra benjaminiana ainda ilumina alguns dos fenômenos da nossa contemporaneidade. Me retenho especialmente na capacidade de contar histórias para vincular nossa ligação uns com os outros e, sobretudo, para dar sentido ao mundo em comum. Narrar a própria história ou a vida de alguém parte da esfera do privado, mas ganha uma dimensão política agregadora, de forma que, ao narrar, realizamos uma reconciliação entre nós mesmos e o mundo da pluralidade. Ainda, a importância do sujeito político que narra é ainda mais sensível para contar outras histórias esquecidas e repensar passados traumáticos. Nesse momento, tentarei dialogar com a obra de Walter Benjamin com a autora Hannah Arendt. Ainda que diferentes entre si, a obra arendtiana deve muito à tradição messiânica do Benjamin, especificamente sobre a história e a narração (Assy, 2011).

A esfera pública é o espaço das aparências onde aparecemos uns aos outros, mostrando quem somos (Kristeva, 2001, 14-15). Ela também delimita aquilo que é público e privado, isto é, aquilo que não pode ser falado ou mostrado. "Os limites do dizível, os limites do que pode aparecer, circunscreve o espaço pelo qual o discurso político opera e certos sujeitos aparecem como atores" (Butler, 2004, 1-2). Só que isso envolve também a decisão daquilo que conta como importante ao domínio público e aquilo que é ignorado. "A esfera pública é constituída em parte pelo quê pode aparecer, e essa regulação define o que conta como realidade e o que não conta" (BUTLER, 2004, 2). Arendt lembra que a vida política é revelada pela ação por meio da narração de fatos (KRISTEVA, 2001, 13). Por isso devemos ser capazes de ouvir além do que podemos, para abrir espaços de narrativas àqueles à quem foram negados o seu aparecimento no público (BUTLER, 2004, 18). Logo, a narrativa é condicionada à existência de um inter-esse, isto é, uma pluralidade. Arendt, por exemplo, ignora os aspectos técnicos de contar uma história, pois, para ela o que importa é a coesão interna que a estória oferece e a arte de "condensar a ação em um momento fora do fluxo do tempo e espaço" (KRISTEVA, 2001, 17) e, assim, o sujeito da estória é identificado. Contar estórias guarda em si a capacidade de agir, de ser revelado e de construir memórias dentro da 
pluralidade de indivíduos (Idem, 2001, 19). "O indivíduo se imortaliza ao se tornar o 'quem' que atua dentro do espaço político e dando origem à uma narrativa memorável" (Idem, 2001, 19).

Por meio de atos e palavras, agimos por meio de um espaço-entre [inbetween] cuja materialidade é inatingível, mas é "tão real quanto o mundo das coisas que visivelmente temos em comum" (ARENDT, 2010, 229). A essa realidade fugaz, Arendt a denomina de teia de relações humanas, vinculada tanto ao mundo objetivo das coisas quanto ao espaço das aparências. Afinal, a revelação do sujeito depende exclusivamente do discurso com os outros. Mas, sobretudo, é por meio dessa teia, no qual indivíduos se revelam, que podemos apreender as estórias sobre quem que se revela ou já se revelou.

É interessante, portanto, considerar a dimensão política da dor e do sofrimento, da vulnerabilidade comum, do trauma decorrentes da violência e da incapacidade do luto (BUTLER, 2004, 19). Certamente, a expressão de dor não faz parte da atividade política, pois ela é capacidade de aparecer e agir, mas certamente partilhamos uma vulnerabilidade comum (Idem, 2004, 19). O sofrimento faz parte do aspecto privado da vida humana, mas a capacidade de falar sobre ele contando sua estória no espaço público é a forma cabível de reconciliarmos com realidade, e podermos perdoar o que passou e prometer novos inícios com os outros (ARENDT, 2010). Não viemos e vivemos no mundo de forma independente dos outros, mas somos parte deles, pois só me apareço como "alguém" diante da pluralidade, e é assim que as redes entre nós são construídas (ARENDT, 2010; BUTLER, 2004, 22-25).

Certamente, a violência sofrida fisicamente nos impede de aparecermos em público, mas a capacidade de contar desse sofrimento permite nos libertar dessa memória. O mecanismo político primordial para que se possa começar de novo é o perdão, pois é por meio dele que o ser ativo se liberta e consegue enxergar e reconhecer o "alguém" que até então ele negava-Ihe existência (ARENDT, 2010, 301-302).

Benjamin, por sua vez, é um autor que se volta tanto aos gêneros literários (como no fragmento do "Narrador") como a escrita da história, seja na sua dimensão autobiográfica, presente na "Infância em Berlim", seja na história 
coletiva, presente nas "Teses sobre a História" (GAGNEBIN, 2014, 218). Por isso:

A questão da memória é inseparável de uma reflexão sobre a narração, bem como de uma história ficcional da própria vida, da História de uma época ou de um povo. E as formas de lembrar e de esquecer, como as de narrar, são os meios fundamentais da construção da identidade pessoal, coletiva ou ficcional (Gagnebin, 2014, 218).

Portanto, ainda que talvez mais preocupado com o processo escrito em alguns fragmentos, há uma preocupação sobre a incapacidade de narrar dos sobreviventes da $1^{a}$ Guerra revelam uma experiência de choque: incapacidade de contar as lembranças numa ordem simbólica. Certamente, não podemos mais recorrer à um narrador épico, aquele que narra uma tradição oral, mas a narrativa enquanto $o$ ato de falar e transmitir com a presença de um ouvinte é fundamental para a experiência política per se, pois assim nos constituímos enquanto sujeitos. Cabe dizer que tanto o sujeito arendtiano e benjaminiano não são fechados em si mesmos. O processo de contar a própria história relembra a fugacidade e fragilidade da própria constituição de subjetividade - e nossa capacidade de nos afetar com as demais narrativas.

Aqui cabe uma ressalta, contudo. Como Assmann argumenta, na memória não heroica e a concepção de um self danificado (isto é, na fragilização do indivíduo), há uma dificuldade evidente em traduzir o trauma em símbolos ou signos. Ainda que contar o que aconteceu e a experiência direta seja uma forma de se reconciliar com a realidade, "o trauma estabiliza uma experiência que não está acessível à consciência e se firma nas sombras dessa consciência como presença latente" (ASSMANN, 2011, 277). Dito de maneira mais direta: "as palavras não incorporam o trauma nelas mesmas" (Idem, 2011, 277). A dificuldade está, portanto, em traduzir, por exemplo, a tortura em uma esfera pública - especialmente por ser uma experiência no âmbito do íntimo. A tortura não abandona o torturado, mas como fundamentar essa experiência em uma potencialidade de ação?

O trauma é a impossibilidade da narração, pois torna o corpo uma superfície de gravação que não pode ser expressa totalmente no campo narrativo (ASSMANN, 2011, 283). Talvez a concepção de trauma do filósofo Jean-François Lyotard possa oferecer algum dispositivo de saída. Assmann Doutoranda em Relações Internacionais no Instituto de Relações Internacionais da PUC-Rio e mestre em Direito Constitucional e Teoria do Estado pela mesma instituição. Brasileira, residente no Rio de Janeiro, 
conta que Lyotard descreve a possibilidade de narrar o holocausto de uma maneira coletiva com uma estratégia persistente de conservação: "Lyotarde alça o recalcamento, paradoxalmente, à condição de uma norma, à medida que explica a traumatização como a única forma adequada de relação com 0 holocausto" (ASSMANN, 2011, 280).

[...] Lyotard recomenda ao espírito essencial o trauma como forma de referência coletiva ao crime coletivo do holocausto, e com isso transforma em opção a quintessência do que acontece em um ato de desautorização extrema. Lyotard recomenda o trauma como o estabilizador adequado para a recordação do holocausto (Assmann, 2011, 281).

A estabilização do trauma, para Lyotard, é um mecanismo de resistência à superação do passado. Isso funciona como a denúncia do que aconteceu e para que não se repita mais. Por isso, a construção de monumentos é vista de forma cética por autor, pois representa o esquecimento - como se o que aconteceu foi superado pela coletividade. Aqui não se trata de uma defesa de um certo vitimismo; ao contrário, visto que a experiência traumática nunca pode ser traduzida totalmente em palavras, a recordação daqueles que viveram e que contam podem fornecer o imperativo constante do para que não se esqueça e para que não se repita.

O reconhecimento da vulnerabilidade, então, pode ser um fator que aumenta ou diminui nossa solidariedade com os outros. A vulnerabilidade aqui no sentido de ouvir para além do que está sendo dito e enxergar para além do que está sendo mostrado. Expor e falar sobre a dor é "colocar meu direito ontológico de existir" no espaço público (BUTLER, 2004, 132), reconhecendo o fato de que ser-do-mundo só é possível com os outros, em uma relação, portanto, de amor ao mundo. O espaço público é norteado pelo princípio de que cada indivíduo tem direito a aparecer na sua permanência no mundo, e não precisa estar vinculado necessariamente à um território delimitado. Ele surge no momento em que os indivíduos se reúnem entre si para discutir questões mundanas. Por isso, a frase de Péricles "aonde quer que você vá, você será uma polis" reflete a concepção de "cada um tem o direito de pertencer ao espaço político" (BIRMINGHAM, 2006, 59). 
Nesse sentido, Benjamin está preocupado com as condições contemporâneas de contar e narrar histórias, em um cenário no qual a experiência se esvai diante de um tempo capitalista pautado numa lógica de progresso. Como Gagnebin ressalta (2014), Benjamin utiliza com frequência o recurso da história oral não como um recurso nostálgico, mas como uma espécie de pulsão da narração, conforme discorre a autora (GAGNEBIN, 2014, 222). Contudo, o tempo ao qual a modernidade nos apresenta impacta seriamente a possibilidade de narrar. Ela ainda existe, mas não consegue transmitir uma "experiência comum" (Erfahrung) e, por isso, narrar histórias se apresenta como uma experiência fraturada (GAGNEBIN, 2014, 225).

Além disso, a transmissão da experiência implica uma concepção de subjetividade política intimamente conectada à memória. Não é à toa que a infância aparece, para Benjamin, enquanto um lugar privilegiado do encontro "singular com aquilo que vem de longe, com os mortos e o passado" (GAGNEBIN, 2014, 227-228). A mão infantil que adentra o armário mergulhando na meia não é, segundo Gagnebin, uma leitura particular privada, mas sim as expedições à memória e à lembrança "que só pode se articular enquanto experiência história mais vasta" (GAGNEBIN, 2014, 230).

Narrar é uma profunda redenção aos que não estão mais presentes, à tradição perdida, à ressignificação da tradição no presente. Narrar expressa, portanto, uma ontologia de ação ao ressignificar o self durante a fala e seu lugar no mundo das coisas. É um ato de ruptura à linearidade da História e é o resgaste dos elementos miúdos, delicados, invisíveis, esquecidos. Portanto, narrar implica uma reconciliação do indivíduo com o mundo que compartilha - em uma experiência comum - com uma pluralidade. Narrar revela um sujeito, um "alguém" que até então, se um ouvinte, não existe politicamente.

Narrar é sempre um novo começo e, por isso, o indivíduo é ele mesmo um iniciador - pois guarda em si o elemento da irrupção de novos processos. Assim como o Primo Levi sobrevive para contar o que aconteceu para ele se libertar (suas palavras), ${ }^{5}$ a possibilidade de contar o que aconteceu na

5 "O livro foi escrito para satisfazer essa necessidade em primeiro lugar, portanto, com a finalidade de liberação interior. Daí seu caráter fragmentário: seus capítulos foram escritos não em sucessão lógica, mas por ordem de urgência" (Levi, 1988, 8).

Doutoranda em Relações Internacionais no Instituto de Relações Internacionais da PUC-Rio e mestre em Direito Constitucional e Teoria do Estado pela mesma instituição. Brasileira, residente no Rio de Janeiro, 
pluralidade - ou a possibilidade de ser ouvido e visto - direciona para a política, no qual o único sentido pode ser a liberdade. O retorno da atividade política é, portanto, fundamental para a atividade do pensar e para a emergência do poder. Eles são mecanismos vitais para garantir o espaço público e a conservação da espontaneidade dos indivíduos. A memória pode ser ressiginificada na presença de outros e no espaço público. Por isso, a fé na promessa principal da política: a possibilidade de estabelecer novos começos e processos, pois "o início é como um deus que, enquanto mora entre os homens, salva todas as coisas" (Platão apud Arendt, 2010, 44).

\section{REFERÊNCIAS}

ARENDT, Hannah. A Condição Humana. 11aㅡ Ed. Rio de Janeiro: Forense Universitária, 2010.

. Homens em Tempos Sombrios. São Paulo: Companhia das Letras, 2008.

ASSMANN, Aleida. Espaços da Recordação: formas e transformações da memória cultural. Campinas: Editora da Unicamp, 2011.

ASSY, Bethânia. Empowering the Subject of Injustice: Victim's' Historiography, Memory and Testimonial Narrative. Simpósio: Law's ContraArchive. Londres - Birkbeck University, 2013.

_. Hannah Arendt and the Jewish Messianic Tradition - Heroic Action and the Politics of the Defeated. Trumah - Zeitschrift der Hochschule für Jüdische Studien Heidelberg, v. 20, p. 50-68, n. 2011.

BENJAMIN, Walter. O Anjo da História. João Barrento [trad]. Lisboa: Assírio \& Alvim, 2010a.

. Experiência e Pobreza. IN: BENJAMIN, Walter. Obras Escolhidas I: magia e técnica, arte e política. 12ª Edição. São Paulo: Brasiliense, 2010, p.114-119. 
_. O Narrador: considerações sobre a obra de Nikolai Leskov. In_ _ BENJAMIN, Walter. Obras Escolhidas I: magia e técnica, arte e política. 12ª Edição. São Paulo: Brasiliense, 2010, p.197-221.

. Sobre o Conceito de História. In_ : BENJAMIN, Walter. Obras Escolhidas

I: magia e técnica, arte e política. 12ª Edição. São Paulo: Brasiliense, 2010, p.222-234.

. Rua de Mão Única: alarme de incêndio. In__: BENJAMIN, Walter. Obras Escolhidas II: Rua de Mão Única. São Paulo: Brasiliense, 1987.

_. Infância em Berlim por volta de 1900: armários. In_ _ BENJAMIN, Walter. Obras Escolhidas II: Rua de Mão Única. São Paulo: Brasiliense, 1987.

BIRMINGHAM, Peg. Hannah Arendt and Human Rights: the predicament of common responsibility. Bloomington: Indiana University Press, 2006.

BUTLER, Judith. Precarious Life: the powers of mourning and violence. Londres: Verso, 2004.

DUARTE, Pedro. Estio do Tempo: romantismo e estética moderna. Rio de Janeiro: Zahar, 2011.

GAGNEBIN, Jeanne Marie. Limiar, Aura e Rememoração: ensaios sobre Walter Benjamin. São Paulo: Editora 34, 2014.

_. Lembrar, Escrever, Esquecer. São Paulo: Editora 34, 2009.

_. Walter Benjamin ou a História Aberta. In__: BENJAMIN, Walter. Obras Escolhidas I: magia e técnica, arte e política. 12a Edição. São Paulo: Brasiliense, 2010, p.7-20.

LEVI, Primo. É Isto Um Homem?. Rio de Janeiro: Rocco, 1988.

LÖWY, Michael. Walter Benjamin: aviso de incêndio. São Paulo: Boitempo, 2005.

Doutoranda em Relações Internacionais no Instituto de Relações Internacionais da PUC-Rio e mestre em Direito Constitucional e Teoria do Estado pela mesma instituição. Brasileira, residente no Rio de Janeiro, Brasil. E-mail: mferreira2812@gmail.com 
KRISTEVA, Julia. Hannah Arendt: life is a narrative. Toronto: University of Toronto Press, 2001.

MATE, Reyes. La Historia de los Vencidos. In: _. La Razón de los Vencidos. Barcelona: Anthropos, 1991, p.163-227.

RICOEUR, Paul. A Memória, a História, o Esquecimento. Campinas: Editora da Unicamp, 2007.

SONTAG, Susan. Sob o Signo de Saturno. Rio de Janeiro: L \& PM, 1986. 